\title{
PARCERIA SOBRADPEC E CBC
}

\author{
Saul Goldenberg*, Alberto Schanaider*, Alberto Goldenberg* \\ *Conselho Diretor SOBRADPEC
}

O Prof. Alcino Lázaro da Silva teve inspiração divina ao publicar na Revista do CBC o artigo CBC E SOCIEDADES CIRÚRGICAS ${ }^{1}$. Alguns trechos extraídos deste artigo:

"Os convênios entre sociedades são saudáveis porque reatam vínculos sem qualquer um dos conveniados se descaracterizar ou se despersonalizar. Cirurgia Experimental e o Fórum de Pesquisa podem se unir, num convênio em que encontrarão eco para um grupo de cirurgiões. Um tipo de cirurgião que denominamos Cirurgião Acadêmico. Convênio no qual se entregaria à Sobradpec a orientação do Fórum de Pesquisa do CBC".

Em 5 de outubro de 2009, na sessão de abertura do XI Congresso Nacional de Cirurgia Experimental da SOBRADPEC, no Auditório de CBC no Rio de Janeiro o Prof. Edmundo Machado Ferraz, Presidente do CBC (gestão 2008-2009) proclamou em seu discurso: "O CBC quer também ser a casa da SOBRADPEC. Venham juntar-se a nós, temos muito a fazer pela cirurgia brasileira. SOMAR sempre foi a palavra mágica entoada por Saul Goldenberg." "2 Levou a proposta ao Diretório Nacional para que a SOBRADPEC viesse integrar-se ao Centro de Pesquisas do CBC - CEPESQ, constante do Estatuto (art. 71).

O Prof. Gaspar de Jesus Lopes Filho assumiu a Presidência do CBC (gestão 2010-2011) e comunicou que em 29 de julho de 2009 o Diretório Nacional do CBC referendou o texto do contrato, concretizando o trabalho cooperativo entre as duas sociedades. O Centro de Pesquisas do CBC (CEPESQ) será dirigido por um Conselho constituído por cinco Membros. A SOBRADPEC será responsável pela indicação dos cinco membros, sendo um de seus membros o presidente eleito por seus pares. A constituição fica a seguinte:

Presidente do CEPESQ - Alberto Schanaider, SOBRADPEC/CBC

Alberto Goldenberg, SOBRADPEC/CBC

Edna Frasson de Souza Montero, SOBRADPEC/CBC

Aldo da Cunha Medeiros, SOBRADPEC/CBC

Ruy Garcia Marques, SOBRADPEC/CBC

O Forum de Pesquisa do CBC e os Congressos da SOBRADPEC permanecem como estão. A SOBRADPEC poderá colaborar com o Forum do CBC.

Deverá ser criado um calendário de eventos científicos, para a divulgação e a difusão das pesquisas na área cirúrgica realizadas pelos pesquisadores membros e não membros do $\mathrm{CBC}$ e da SOBRADPEC dos diversos centros de pesquisa de todo país. Deverá ser organizado um cadastro nacional dos centros de pesquisa na área cirúrgica, que inclua os capítulos e regionais de ambas sociedades.

Faz-se necessário definir a interação entre as Regionais da SOBRADPEC e os Capítulos do CBC. O CEPESQ deve integrar os Presidentes das Regionais da SOBRADPEC e os Mestres dos Capítulos do CBC.para nortear a realização de eventos em seus Estados em mútua cooperação.

Consolida-se uma união em prol da cirurgia brasileira.

${ }^{1}$ Lázaro da Silva A. CBC e sociedades cirúrgicas. Rev Col Bras Cir. 2009;36(5):367-8

${ }^{2}$ Ferraz EM. O CBC e a SOBRADPEC. Editorial. Acta Cir Bras. 2010,25(2):131. 